\title{
Variability of Arctic sea-ice cover at decadal to millennial scales: the proxy records
}

Anne de Vernal

\author{
Sea-ice observations cover only a few decades, making proxy reconstructions a necessity to document natural \\ variability. Proxy data suggest resilient sea ice in the Canadian Arctic, but large variations in seasonal extent in the \\ Pacific Arctic and subarctic Atlantic.
}

Sea ice is an important component of the climate system as it is responsible for Arctic amplification through ice-albedo feedbacks and because it controls the exchanges of heat and gas at the ocean-water interface. Sea-ice formation and melt vary in response to incoming energy and depend upon stratification and thermal inertia in the upper water layer, which are functions of salinity. They also vary in space in relation with surface-ocean and atmospheric currents that form pack ice in convergence zones and redistribute sea ice in subpolar seas.

Satellite observations of Arctic sea ice are continuous since 1979. They show large annual timescales, from summer (September $\sim 6.3 \pm 1.110^{6} \mathrm{~km}^{2}$; see limit in Figure 1) to winter (March 15.5 $\pm 0.510^{6} \mathrm{~km}^{2}$ ), which represent about $60 \%$ of the change in the coverage (see http://nsidc.org/data/ seaice_index). Beyond seasonal variation, a multidecadal decreasing trend is recorded, with a larger change in summer $13.3 \%$ per decade) than winter (2.7\% per decade). The decrease in summer sea-ice extent is correlated with the rise of surface air variations of Arctic sea-ice extent at intra-

temperature $\left(r^{2} \sim 0.63\right)$. However, the sea-ice decline is non linear and could result, at least in part, from internal variability (Swart et al. 2017). Longer-than-satellite time series are therefore needed for a proper assessment of trends and to document the full range of sea-ice variability under natural forcings and feedbacks.

\section{Reconstructing past sea ice}

The development of time series covering centuries to millennia is a challenge. Among approaches used to document past sea ice, one consists of the compilation of historical archives such as ship logs, diaries and any sea-ice-related observations (e.g. ACSYS 2003). Available information encompasses a few centuries and mostly covers the subarctic North Atlantic where human populations have settled. It illustrates variations in seasonal extent of sea ice in areas located along the winter-spring sea-ice edge, with multidecadal variations, for example in the Barents Sea (Vinje 2001), or the secular trend since the 19th century, for example off Iceland (Lamb 1977). The data also show clear regionalism, which point to complex

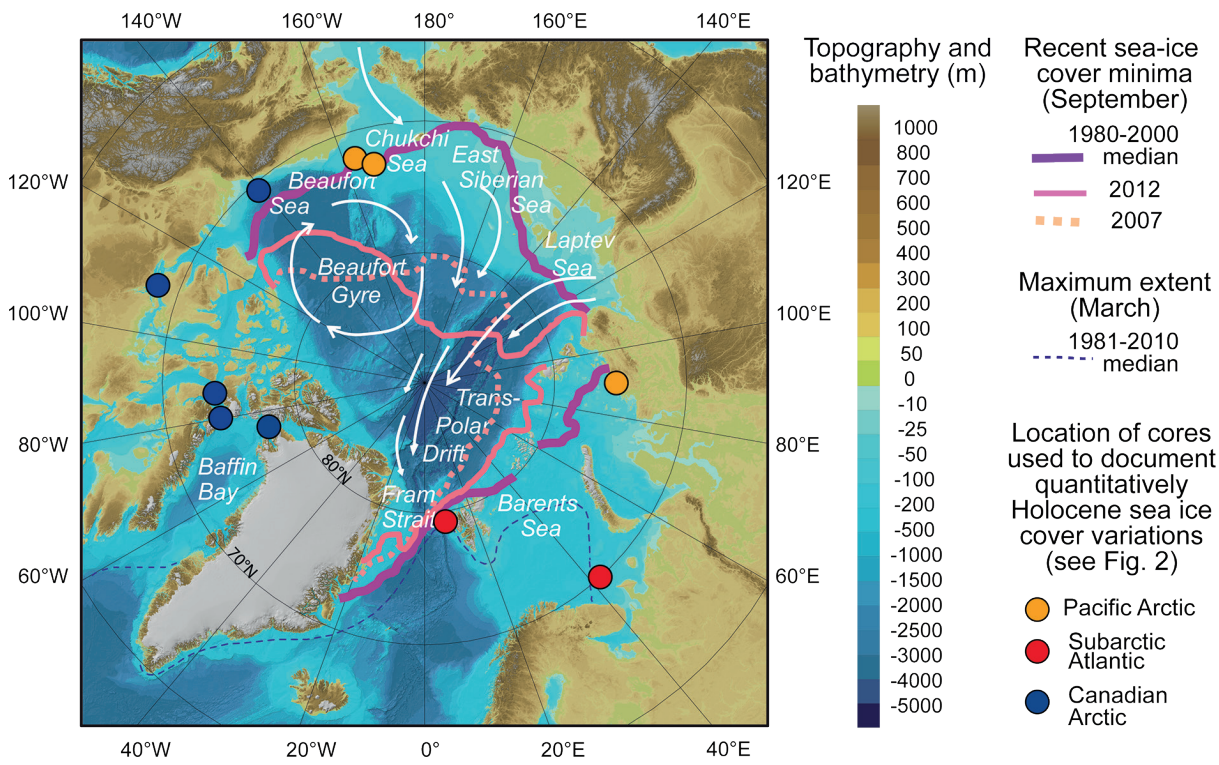

Figure 1: Map of the Arctic Ocean with limit of minimum sea-ice-cover extent (mean from 1980 to 2000; minima of 2012 and 2007), main currents paths (white arrows) and location of cores used to illustrate the circum-Arctic sea-ice-cover variations during the Holocene (Fig. 2). dynamics of the seasonal sea ice and prevent spatial extrapolation from isolated sites.

Another approach to reconstruct Arctic seaice extent uses its relationship with climate to derive time series based on the analysis of annually resolved climate-related data from tree rings and ice cores of circum-Arctic regions (Kinnard et al. 2011). This approach allowed for the development of a comprehensive 1400-year record of late summer Arctic sea-ice extent, which suggests natural variability ranging mostly from $\sim 9$ to $1110^{6}$ $\mathrm{km}^{2}$ (Kinnard et al. 2011). The set of data is, however, heterogeneously distributed with very rare data points from the Russian Arctic, which is the most critical region with respect to the recent decline in sea-ice cover.

\section{Most studies to document past Arctic sea} ice on a long timescale use biogenic proxies from marine sediment cores, based on the assumption that sea ice controls environmental conditions such as light, temperature and salinity, thus playing a determinant role on species' distribution, primary productivity and biogenic fluxes to the sea floor (de Vernal et al. 2013a). Microfossils routinely recovered in marine sediments, such as ostracods or foraminifers, were used as paleoceanographic tracers, but their relationship to sea ice is indirect (e.g. Cronin et al. 2010; Polyak et al. 2013). Among marine microorganisms yielding microfossil remains, diatoms and dinoflagellates appear to be more directly related to sea ice as they include taxa associated with sea ice. For example, some diatom species blooming in spring sea ice produce organic biomarkers (IP25), providing direct indications on sea-ice occurrence (e.g. Belt et al. 2007). Many IP25 time series have been produced since 2007, but the curves remain qualitative in the absence of calibration (e.g. Belt and Müller 2013; Stein et al. 2017). Quantitative estimates of sea-ice cover were proposed from transfer functions based on the calibration and the application of modern analogue techniques. In particular, regional data sets of diatom distributions in the surface sediments were used to quantitatively estimate spring sea-ice concentrations from transfer functions, notably in the eastern Baffin Bay (Sha et al. 2014). Hemispheric-scale databases of dinoflagellate cyst populations 


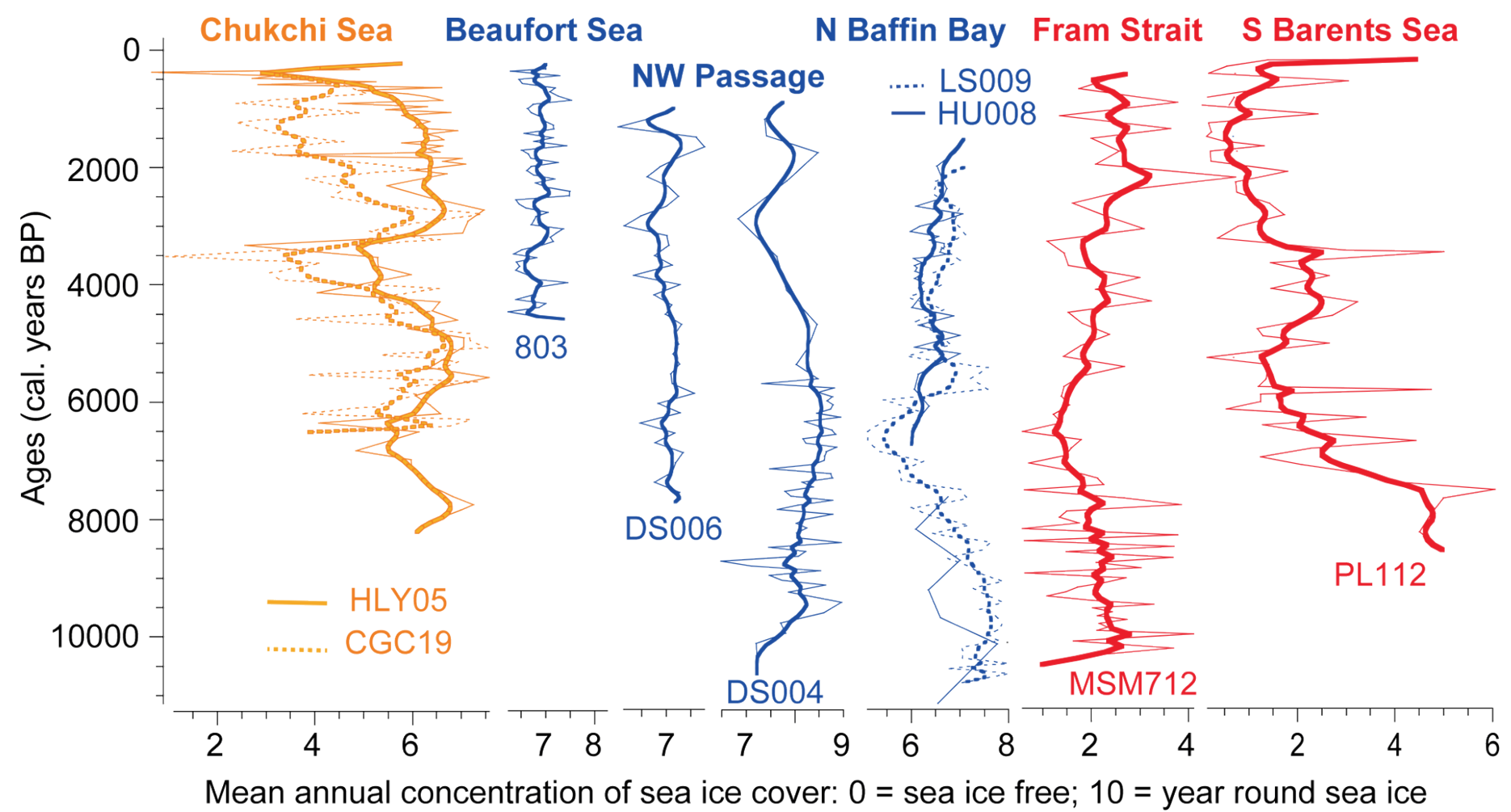

Figure 2: Reconstructed sea-ice cover versus ages during the Holocene. The thin lines correspond to estimates and the thick lines are the smoothed values, which better illustrate millennial-scale variations.

allowed the application of modern analogue techniques for quantitative reconstructions of seasonal sea ice at many sites in the Arctic and subarctic seas (de Vernal et al. 2013b; See examples in Fig. 2).

The limitation of marine sea-ice proxies Regardless of the approach, the marinebased sea-ice records suffer from several caveats:

(1) The temporal windows of proxy-data. A sediment slice ( $1 \mathrm{~cm}$ usually) may represent decades to centuries or millennia, depending on sedimentation rates ( $\mathrm{mm}$ per year to $\mathrm{cm}$ per thousand years) and bioturbation. This is problematic in the central Arctic Ocean where accumulation rates are particularly low.

(2) The "modern" relationships between the proxies and sea ice are defined from the comparison of surface sediment samples and recent observations, which usually do not encompass the same time window. This is an important source of errors when calibrating transfer functions and applying modern analogue techniques.

(3) Each record has first a local to regional value. The spatial distribution of marine-core records of past sea ice is not dense enough for extrapolation at the scale of the Arctic Ocean and subarctic seas. The rarity of quantitative sea-ice estimates in the Russian Arctic, where the largest variability is presently recorded, is a critical issue.

(4) Year-round ice-free conditions and seasonal sea ice can be assessed from many proxies, but perennial or multiyear sea ice is more difficult to reconstruct. One ostracod taxon parasite of sea-ice nematode was used to assess multiyear sea ice in the central Arctic (Cronin et al. 2013), but perennial ice cover is usually deduced from negative evidence (nil productivity of primary producers).

Circum-Arctic sea ice during the Holocene Despite limitations, the marine data provide clues on sea-ice cover variations with time windows ranging from decades to centuries, thus yielding smoothed records. At the scale of the Holocene, proxy-data suggest limited variations in general, with likely resilient perennial sea ice in the central Arctic Ocean, but greater variations in the seasonal sea ice as expressed in terms of spring sea-ice concentration (Sha et al. 2014) or number of months of sea ice (de Vernal et al. 2013b) in the Arctic and subarctic seas which are within the limits of winter sea ice. In other words, the variability of sea-ice cover as reconstructed from marine proxies illustrates more the seasonality of its extent and concentration than the actual changes in the Arctic-wide extent of sea ice. The amplitude of local changes during the mid-and late Holocene seems to be mostly comprised within the range of interannual variations as recorded during the last decades. At some sites, variations from a dominant mode to another (low to high sea ice) is recorded with a pacing ranging from multidecadal to millennial scales that may, however, depend upon the time resolution achieved by the analyses. The records based on a standardized quantitative approach, allowing comparison at the circum-Arctic scale, show limited changes and persistent sea ice in the Canadian Arctic, but large-amplitude changes closer to the Pacific and Atlantic gateways (de Vernal et al. 2013b; Fig. 2), where inter-basin exchanges (freshwater and heat fluxes) seem to result in a higher variability in sea ice cover. They also suggest diachronous, if not opposite, changes in the western (Pacific) Arctic versus eastern (Atlantic) Arctic at millennial scales, which might well illustrate shifts from dominant Arctic dipole pattern (Wang et al. 2009) to strong polar vortex leading to more stable Arctic sea-ice cover.

\section{AFFILIATIONS}

'GEOTOP, Université du Québec à Montréal, Canada CONTACT

Anne de Vernal: devernal.anne@uqam.ca

\section{REFERENCES}

Belt ST et al. (2007) Org Geochem 38: 16-27 Belt ST, Müller J (2013) Quat Sci Rev 79: 9-25

Cronin TM et al. (2010) Quat Sci Rev 29: 3415-3429

Cronin TM et al. (2013) Quat Sci Rev 79: 157-167

de Vernal A et al. (2013a) Quat Sci Rev 79: 1-8

de Vernal A et al. (2013b) Quat Sci Rev 79: 111-121

Kinnard C et al. (2011) Nature 479: 509-512

Lamb HH (1977) Climate History and the Future, vol. 2. Methuen, $835 \mathrm{pp}$

ACSYS (2003) ACSYS Historical Ice Chart Archive (15532002). IACPO Informal Report No. 8. Tromsø, Norway: Arctic Climate System Study

Polyak L et al. (2013) Quat Sci Rev 79: 145-156 Sha L et al. (2014) Palaeogeogr Palaeoclimatol Palaeoecol 403: 66-79

Stein R et al. (2017) J Quat Sci 32: 362-379

Swart NC et al. (2017) Nat Clim Change 5: 86-89

Vinje T (2001) J Clim 14: 255-267

Wang J et al. (2009) Geophys Res Lett 36: L05706 